\title{
A SPANISH UNIVERSITY CASE STUDY: USER'S PERCEPTION OF BLENDED METHODOLOGY USED FOR ENGLISH FOREIGN LANGUAGE LEARNING
}

\author{
M. Teresa Martín de Lama \\ University Antonio de Nebrija
}

\begin{abstract}
Blended learning at universities has emerged as a solution to address the need of fostering students' independent and life-long learning as well as foreign language acquisition. The methodology combines oncampus and on-line tuition. Existing literature has largely discussed the advantages and disadvantages about blended learning, e-learning communication tools (synchronous and asynchronous), and language learning aided by computers. However, more research is still necessary to notice how students and teachers perceive this methodology in foreign language learning. In this line, the Master's Degree in Bilingual Education at Nebrija University (Spain), which is wholly run through blended learning, has as a main aim to raise students' level of English from a B2 to a C1. During its first year of implementation, a research was carried out to analyze the participants' opinion on the benefits of the blended-learning tools used for English learning; detect possible deficiencies; and to provide recommendations for future foreign language teaching and learning.
\end{abstract}

Keywords: Blended learning, e-learning, on-campus and on-line tuition, synchronous and asynchronous communication, CALL, foreign language teaching and learning. 


\title{
UN ESTUDIO DE CASO EN LA UNIVERSIDAD ESPAÑOLA: PERCEPCIÓN DE LOS USUARIOS SOBRE LA METODOLOGÍA SEMI-PRESENCIAL PARA EL APRENDIZAJE DEL INGLÉS COMO LENGUA EXTRANJERA
}

\begin{abstract}
RESUMEN. La enseñanza semi-presencial en la universidad ha surgido como una solución para fomentar el aprendizaje autónomo y permanente, asi como la adquisición de lenguas extranjeras. La metodología combina clases presenciales y tele-presenciales. La bibliografía existente discute sobremanera las ventajas y desventajas de la enseñanza semi-presencial, las herramientas de comunicación tele-formativas (sincronas $y$ asincronas), y el aprendizaje de lenguas asistidas por ordenador. Sin embargo, más investigación es necesaria para mostrar la percepción de estudiantes y profesores sobre dicha metodología para el aprendizaje de lenguas extranjeras. El Máster semi-presencial en Educación Bilingüe de la Universidad Nebrija (España), cuya docencia es completamente semipresencial, tiene como uno de sus principales objetivos elevar el nivel de inglés de los estudiantes de B2 a C1. En su curso inaugural se llevó a cabo una investigación para analizar la opinión de los participantes sobre la efectividad de las herramientas, detectar posibles deficiencias y aportar recomendaciones para la futura enseñanza y aprendizaje de lenguas.
\end{abstract}

Palabras clave: Enseñanza semi-presencial, tele-formación, clases presenciales y semi-presenciales, comunicación síncrona y asíncrona, ELAO, aprendizaje y enseñanza de lenguas extranjeras.

Received 15 March 2013

Revised version accepted 30 September 2013

\section{INTRODUCTION}

The Bologna Process which European Higher Education Institutions are nowadays involved in affects the organisation and development of university studies, regarding students' autonomous, life-long and foreign language learning (Europen Commission 2006, 2013; Halbach et al. 2010, 2013). In this line, blended learning has been proposed as an educational alternative which can allow citizens acquire independent learning, by integrating on-campus classes (with face-to-face tuition) and on-line sessions (with synchronous and asynchronous computermediated communication tools) (Dziuban, Hartman and Moskal 2004); Carman 2005; Stacey and Gerbic 2008).

Literature regarding the possible benefits and drawbacks of blended learning being applied to higher education contexts in general can be found (Garrison and Kanuka 2004; Bonk and Graham 2004). There are also surveys carried out at higher education which now start to show interest in evaluating blended- 
A SPANISH UNIVERSITY CASE STUDY: USER'S PERCEPTION OF BLENDED METHODOLOGY USED...

learning programmes through teachers and students' perceptions (Bonk, Kim and Zeng 2005; Albrecht 2006). Many other focus on the benefits and drawbacks of using synchronous and asynchronous e-learning methods (Hrastinkski 2008) or Computer-Assisted Learning tools (Hubackova and Ruzickova 2012). Furthermore, most of the empirical research at universities has studied the matter mainly from a quantitative perspective, comparing, for example, the results obtained by students and the number of university dropouts in traditional and blended modalities (McLaren, Koedinger and Scheider 2004) or focusing on the benefits of specific computer-mediated tools for subject learning (Singh 2003). However, more research is necessary in order to demonstrate the benefits of this methodology used for foreign language learning in particular, based on the opinion of teachers and students.

The Master's Degree in Bilingual Education at Nebrija University (Madrid, Spain) was launched in the academic year 2011/2012 in blended-learning modality with the aim of training prospective teachers in bilingual education; improving their communicative competence in English from a B2 entrance level to a $\mathrm{C} 1$ exit level; and fostering their autonomous learning.

This present research was carried out during first year of implementation of the degree to analyze the perceptions of both university teachers and students on the effectiveness of the blended-learning methodology in EFL learning.

In this article, a brief conceptual framework on foreign language learning linked to blended learning methodology will be presented first, followed by the description of the research methods, the analysis and discussion of the results obtained, and some final conclusions.

\section{CONCEPTUAL FRAMEWORK}

\subsection{FOREIGN LANGUAGE LEARNING}

In the last decades, foreign language learning has become a key issue in all European countries (European Commission 2006). The main aim is to improve the students' communicative competence through the adoption of a communicative approach which implies the systematic and progressive acquisition of linguistic, sociolinguistic, pragmatic, discourse and strategic competences (Ellis 2004). Communicative competence is measured according to the levels of competence or descriptors in the Common European Framework of Reference for Languages (CEFRL) (Little 2011). Different techniques have been designed under the communicative approach (Harmer 2010), in which, on the one hand, the exposure to the target language must be intensive and the input needs to be varied and authentic (Richards 2001) and, on the other hand, tasks 
have to be based on meaningful and real communicative activities so that students and teachers can interact, work together using the target language and cooperate (Long 2005) to progress in their interlanguage towards a better language use (Harmer 2010).

\subsection{BLENDED-LEARNING METHODOLOGY}

Internet and ICT tools, first introduced in educational contexts as additional material to enhance face-to-face learning, soon started to be used as learning platforms for pure on-line (distance) learning. Historically, face-to-face teaching and on-line instruction have been separated because of the media available and the instructional methods used in each instance. Digital learning is considered distributional, which means that the same information can be effectively delivered to a greater audience. These distributed learning contexts traditionally emphasized the interaction between learners and materials, whereas face-to-face settings prioritized human to human interaction (Bonk and Graham 2004). However, distributed learning environments are now increasingly taking on the place previously reserved for face-to-face, through tools like "computer-supported collaboration, virtual communities, instant messaging, blogging, etc.” (Bonk and Graham 2005: 20).

As blended learning "combines the effectiveness and socialization opportunities of the classroom with the technologically enhanced active learning possibilities of the online environment" (Bonk and Graham 2005: 18), it can provide "the right learning at the right time and in the right place for every individual" (Thorne 2003: 18). It integrates the online communication resources with traditional face-to-face tuition, reorganizing the teaching and learning dynamics, in order to give solution to various different contextual needs with high levels of effectiveness (Rossett and Vaughan 2006; Garrison and Vaughan, 2008). Moreover, although blends can differ greatly from each other, some common elements can be pointed out: face-to-face sessions, independent and practical activities, evaluation tools and procedures, virtualized contents and distributed resources, group work, tutors and communicative learning tools (Alcides Parra 2008; Bartolomé 2008; Bonk and Graham 2005).

\subsubsection{E-learning communicative tools}

Adopting a blended-learning methodology implies the use of synchronous and asynchronous communicative learning tools (Sharma and Barrett 2007). Asynchronous tools, in which learning does not need to take place in a live event, are mainly characterized by their flexibility, as students can access learning materials when and how it is needed; their gradation, in order to help 
A SPANISH UNIVERSITY CASE STUDY: USER'S PERCEPTION OF BLENDED METHODOLOGY USED...

students progressively adquire knowledge; and, their reflectivity, as learners can spend time on their own thinking about contents, tutorials, tests and practical activities (Hrastinski 2008). Synchronous learning experiences, on their part, occur simultaneously between different participants, and introduce some dynamism to traditional on-line learning. For Hrastinski (2008), these tools are featured as flexible, since online classes are usually scheduled as to permit learnes reconcile their studies with other personal and professional activities; and, interactive, because they allow real-time communication, collaboration, socialization as well as immediate response and feedback.

Andrews and Haythornwaite (2007) argue that there are three types of communication which e-learning communities can bring about: communication related to content, communication for planning tasks, and communication for providing social support. In the former, students will need to ask or answer questions related to content, share information and express their own ideas. For task planning, students will be required to communicate in order to plan and coordinate work, as well as to negotiate and solve possible conflicts. Finally, in the latter, learners will be asked to express their emotions, provide support and socialize outside class work. Face-to-face interaction, videoconferencing, instant messaging and chats (synchronous tools) can be useful to support learners in socialization and task planning whereas, for more reflective tasks, tools like e-mail, fora, blogs and wikis (asynchronous tools) can be a better choice.

\subsubsection{Computer-Assisted Language Learning (CALL) in Blended Learning}

When considering bended methodology for foreign language learning, the interdisciplinary ${ }^{1}$ Computer Assisted Language Learning (CALL) ${ }^{2}$ tools need to be taken into account as well. The use of Internet and multimedia devices allows students to engage in authentic tasks through activities in attractive and varied formats; to obtain immediate feedback and reinforcement; to adapt contents to their diversity and needs; to develop their autonomy; and to learn in a stress-free and motivational setting (Egbert and Hanson-Smith 2007).

\footnotetext{
1 CALL receives influences from Psychology, Second Language Acquisition and other fields like Artificial Intelligence, Computational Linguistics, Instructional Technology and Design and Human Computer Interaction (Egbert \& Hanson-Smith, 1999; Gamper \& Knapp, 2003).

2 Other related acronyms are: ICALL (Intelligent Computer-Assisted Language Learning), CAI (Computer Assisted Instruction), CELL (Computer-Enhanced Language Learning), TELL (Technology Enhanced Language Learning) or WELL (Web Enhanced Language Learning. The main difference is the focus given to the computer as part of the learning process. CALL will be used here as a general term.

3 Except for the Practicum Module to be fulfilled either in the same or in the next academic year.
} 


\subsection{THE INFLUENCE OF CONSTRUCTIVISM \& CONNECTIVISM IN BLENDED LEARNING}

Although in CALL and in blended learning we can find some behaviourist type of activities, like multimedia drills or multiple-choice exercises, constructivism and connectivism can be considered two main learning and teaching theories which have inspired blended-learning methodology (Siemens, 2004; Downes 2007; Koohang, Riley and Smith 2009). In constructivism learners take on an active and responsible role in knowledge-construction and for that reason the individual mental processes -and differences- when students interact with the medium need to be addressed.

Recently, with Virtual Learning Environments (VLE), learning has acquired a new dimension. As Siemens (2004) explains, in connectivism, knowledge is understood as a process which occurs within an ever-changing environment. For this theory, learning lies in the collectivity of individual opinions. Therefore, it considers that knowledge is within each individual and that we acquire and update this knowledge when we collaborate with other people in learning communities - or social ecologies-. In this view, learning is a process of infinite connections between different information points, from people to people, or from non-human devices (data-bases, libraries, organizations, etc.) to humans (Downes 2007).

As regards the important role of learning communities, Garrison and Kanuka (2004: 98) claim that, whether face-to-face or online, they combine "cognitive, social and teaching presence", and Hrastinski (2008) emphasizes the importance of "personal and cognitive participation" linked to e-learning, the former by increasing motivation for information exchanges, task planning and social support; and the latter by fostering reflection and discussion.

\section{RESEARCH STUDY}

The present research study is based on information gathered from teachers and students' surveys, interviews to teachers and discussion groups with students, as well as from the analysis of students' final grades in the different subjects. It handled quantitative data, but also extended the scope of the study to qualitative aspects, such as the students and teachers' perceptions and opinions about the different tools available and the real use they made of them. In particular, this case study intended to:

1. Show whether or not students can benefit from the use of blendedlearning tools to improve their proficiency in English. 
A SPANISH UNIVERSITY CASE STUDY: USER'S PERCEPTION OF BLENDED METHODOLOGY USED...

2. Notice deficiencies and provide practical recommendations to improve the future development of the programme as regards English language teaching and learning.

\subsection{THE RESEARCH CONTEXT}

The Master's Degree in Bilingual Education at Nebrija University, designed to be fulfilled in one academic year ${ }^{3}$, was run for the most part in English ${ }^{4}$. Besides content learning in English, students also trained their linguistic skills through specific English language courses ${ }^{5}$. This programme is complemented with diverse activities conducted in English as well, like the attendance to a Forum in Bilingual Education, and two four-day linguistic immersion periods with attendance to foreign language teaching methodology workshops along the two terms. Therefore, the intensive use of English as the medium for learning other subjects is considered key in helping students progress from a B2 level of entrance reach a C1 exit level after successful completion of the programme.

\subsection{BLENDED-LEARNING TOOLS USED AT THE PROGRAMME}

The programme combined the tools of the collaborative virtual campus UNNE, based on DOKEOS ${ }^{6}$ with real-time videoconferences and on-campus sessions. Firstly, online classes were easily accessed through the virtual campus on Blackboard Collaborate. These classes were two-hours long, were held three days a week, and represented the $71 \%$ of total tuition time. They were delivered in small groups of eight to nine students ${ }^{7}$ through synchronous videoconferences. Secondly, on-campus sessions were held during five hours at weekends every fortnight. They represented the other $29 \%$ of total tuition time. These classes were delivered in a large group of twenty-one students. Finally, the Virtual Campus was the platform used for asynchronous on-line learning. The tools available were: the agenda and the bulletin boards, through which teachers communicated important dates and clarified information regarding contents, activities, additional resources, exams; the documents, where instructors uploaded syllabuses, contents, activities, annexes; the learning paths, which ordered documents and exercises to guide students through their learning process; the links section, with relevant websites related to the field of each

\footnotetext{
4 With the exception of the subject Psicología e Interlengua, taught in Spanish.

5 Through the subjects Communicative Skills 1, Communicative Skills 2 and Communicative Skills 3 with 4 ECTS each.

6 Nebrija University's own designed UNNE virtual campus. Demo version available.

7 The maximum number of students per on-line group was twelve.
} 
subject; the task boxes, where students uploaded their activities and received feedback from teachers; the self-assessment tests \& exercises in different formats (multiple choice, cloze, gap-filling, relating, open-ended and interactive questions) which could be accompanied by with clarifying comments; the groupings section, where teachers and students could view names and e-mail addresses of participants in class and small group work; the fora, through which students and teachers could discuss topics, raise questions, make comments asynchronically; the chat and the instant messenger, where participants could easily communicate with each other synchronically through voice tools or written messages, or work in groups by starting a videoconference on their own like the one for on-line classes; and, the recording of videoconferences, where students could easily access and re-watch past sessions.

\subsection{RESEARCH DESIGN}

This research study described the features of the elements implied in the teaching and learning blended methodology, and took into account the effects of the different variables in the final usage result. It focused mainly on qualitative aspects, by analyzing students and teachers' opinions about the different tools available and the real use they made of them. Qualitative information was supported by quantitative data like students' final grades in the different subjects, and other minor quantifiable aspects, also gathered through surveys: teachers and learners' age, their expertise with ICT, their location and their personal circumstances while studying/teaching at the programme ${ }^{8}$.

The longitudinal study was carried out by collecting data from the same participants at different points of time throughout the whole academic year 2011/2012. The research was conducted firstly through teachers and students surveys; and, secondly, through interviews to teachers and group discussions with learners. The researcher also coordinated the programme and participated in the research as a teacher of one of the subjects.

\subsubsection{Surveys to Students and Teachers}

Surveys were chosen to collect quantifiable data from a number of teachers and students which could be representative of the whole population. A structured and standardized questionnaire was filled out by participants within

\footnotetext{
8 This data is not significant on its own but in relation to other main variables. Therefore, as this data was gathered through teachers and students' surveys, the results are presented at the end of the corresponding section of each survey results.
} 
A SPANISH UNIVERSITY CASE STUDY: USER'S PERCEPTION OF BLENDED METHODOLOGY USED...

a short time. Some participants completed their surveys at home and sent them to the researcher at different times and through different means (by mail or in person).

Surveys were divided into four thematic blocks of opinion statements: virtual campus, chat and instant messenger, videoconferences and on-campus classes. Since a scale to measure attitudes was necessary, the survey was designed using a 7-levels Likert scale, ranging from "I completely agree" to "I completely disagree". Through the same surveys, participants were also asked to write short pieces of information providing explanations or comments to their asnswers. Finally, it is important to point out that all participants had attended some training and practical sessions about the use of the virtual campus and videoconferences before starting the programme.

At the end of the first term (March 2012), students were asked to fulfill a survey in Spanish. Although the number of students at the Master's course was 21, only 18 of them filled in the survey. Participating students were required to range 20 positive statements about the different blended-learning tools and the use they made of them.

Likewise, along the second term, both first and second term teachers (18 in total) were asked to fill out a 19-items survey in Spanish with similar statements to the ones in the students' survey.

\subsubsection{Students' discussion groups and teachers' interviews}

After having analyzed the results of the surveys, the researcher held discussion groups with 15 out of the 21 students at the end of June. The purpose was to generate spontaneous response, gain deeper understanding of the students' perspectives and clarify some unclear issues. For that purpose, a list of open-ended questions in Spanish was prepared beforehand.

For the same reasons, during the months of March and July 2012, the researcher held semi-structured interviews with 8 out of the 17 teachers, from which 4 of them were first-term instructors and the other 4 taught subjects during the second semester. The main objective was to have a clearer idea about their perceptions inferred from the surveys, and their opinion about other aspects which could not be asked previously.

\subsubsection{Analysis of students' final grades}

As the research intended to measure the improvement of students' proficiency in English after the use of a blended-learning methodology in foreign 
language learning, an analysis of the progression of students' grades along the two semesters was also carried out.

The researcher obtained data about the grades of all students (21) in all the different subjects during the first and the second terms ordinary examination periods (February and June 2012, respectively) and during the retake examination period for both semesters (July 2012). The analysis also compared the grade range obtained at both examination periods.

Most of the students admitted into the course had a B2 entrance level (57\%) or above (29\%). Although the minimum level of English for entrance was a B2, a small number of students with a lower level (14\%) were admitted.

\section{RESULTS AND DISCUSSION}

The results of the study are presented and discussed, after having analyzed the outcomes from surveys, discussion groups, interviews and students' final grades.

\subsection{RESULTS OF STUDENTS' SURVEYS}

As regards the virtual campus tools, generally speaking, most students (86,6\%) found it easy to access the information at the virtual campus. They also thought that both the self-assessment tests and the task-boxes were useful tools for checking right or wrong answers (92\% and 87,6\% respectively).

With regards communication tools, the great majority also admitted not having made a correct and frequent use of the forum for communicating with other participants (45,5\%). Likewise, the chat (instant messenger) seemed much neglected in the everyday running of the programme. Very few students used it for group work $(32,1 \%)$ and just some of them used it for synchronous communication with teachers or classmates (41,1\%). Besides, a minor group of students admitted having worked collaboratively in groups using the chat's videoconference $(42,9 \%)$. Nevertheless, the great majority of students viewed the videoconference as a great improvement over traditional online distance learning (78,9\%), especially as an effective tool for foreign language learning (70,6\%). Through them, they argued, they could "actively practice oral skills, listening and speaking in the same way as if attending face-to-face classes", since they could "work in small groups and interact with each other in real time". Also, the option of expressing their feelings through their emoticons was considered a positive point to take into consideration (74\%), as they resembled "familiar tools like Facebook and twitter". Finally, the possibility of re-watching 
A SPANISH UNIVERSITY CASE STUDY: USER'S PERCEPTION OF BLENDED METHODOLOGY USED...

the recorded sessions was highly valued by learners for content and linguistic revision (92,9\%), as they also "could watch them over and over again".

In general, students felt that the experience of using blended learning for studying had helped them reconcile their studies with their personal lives $(69,7 \%)$ and therefore it had motivated them "to continue studying despite the hard work as we also work in the mornings". When asked about on-campus classes, students declared that attending to these sessions was essential to complement the on-line ones $(96,4 \%)$.

Students' surveys also showed that students were mostly aged 20-25 (55\%). The other big age group was aged 31-40 (36\%) and only 9\% of students were over 41. In addition, the great majority of students (81\%) had previous experience in learning with ICT or used ICT in their daily lives. Only 19\% had no expertise or prior experience in the use of these tools. As students were in general very young, this fact would explain why they showed such a positive view of the on-line tools. However, we cannot disregard the fact that some young learners did not show a high level of satisfaction and were not familiar with ICT tools, which would show that there is digital divide as regards ICT literacy.

In relation to students' location while studying and their working circumstances, the survey illustrated that the great majority of learners (61\%) lived in the same province of the university, or in the neighbouring autonomous communities (29\%). Only 10\% live in a community far away from the university campus. Moreover, $67 \%$ of students were working while studying the programme, whereas $33 \%$ of them only studied. This data, together with the perceptions collected, demonstrate that students were able to accomplish other tasks while studying, as many of the classes were on-line. In this sense, blendedlearning seemed to allow students conciliate their studies with other activities, bringing university closer to students regardless their location.

\subsection{RESULTS OF STUDENTS' DISCUSSION GROUPS}

In general, online classes were easily accessed, except for the following technical problems which students complained about: the connection sometimes shut down; some of the participants could not use the microphone or could not hear properly; at some occasions, participants could not have the microphone or webcams on at the same time; some students and teachers lacked the necessary software in their home computers; the audio and the video systems were not integrated within the on-line class presentations and thus every user started the application on their computers at different times. These problems affected interactivity and group integration in a very negative way. 
About the recorded sessions, although they declared that recordings were "good to review lessons and practice listening", the movement along the recording, although possible, was very slow. Also, thy mentioned that all the elements showed in the original classes were not visible in the recordings, i.e. some internet routes, audio or video files were missing. At other times, when they appeared, they could not be reproduced until the students played them. As they argued, "you could not see which video belonged to each part of the lesson" and "sometimes you could not see the link for the video unless the teacher wrote it on the chat".

As regards the development of their English oral and written skills, students believed that they had improved much, above all, in their listening and speaking skills thanks to the on-line classes. For students, through videoconferences they could "listen to teachers, and speak in English without feeling ashamed when they made mistakes".

The attendance to on-campus classes was considered essential to supplement on-line classes as there they had the opportunity of "meeting classmates and teachers in person" and create a group feeling. These classes were considered more practical than on-line ones. Learners declared that they could "ask more questions, work in small groups and comment on each other's work". In these sessions students felt that "they had more to say than in on-line classes", where teachers mainly gave lectures.

The workshops during the two immersion periods were also very practical and students had the chance to test their real knowledge. They argued that it was a great chance for them to "practice teaching techniques" and "practice oral English".

About the use of the virtual campus tools, for students, some of the functionalities were neglected by teachers. For instance, the agenda was not used as students received the schedule of the classes through other means, and the rest of the information was updated through the bulletin board; also, about the additional links, students commented that having accessed these links would have been useful; finally, the self-assessment tests and exercises, although much appreciated, lacked in students' opinion, further explanations and comments to answers which would have helped them "work further on the topic" and address "difficult (linguistic) issues".

The forum was one of the least used tools in the virtual campus. Students reaffirmed their opinion of it not being useful for expressing their opinion or for collaborative work, as they found other ways of communicating ("Facebook, messenger, etc."). Teachers hardly opened discussion threads or fostered group work through fora. Besides, students reported that, as answers from teachers in 
A SPANISH UNIVERSITY CASE STUDY: USER'S PERCEPTION OF BLENDED METHODOLOGY USED...

the forum were delayed for weeks, learners wrote an e-mail directly to the Coordinator or to the teacher instead.

The chat (instant messenger) was introduced at the university later at the beginning of the second term, so neither teachers nor students had the chance to receive formal training in this tool. This reason might explain why these tools were not very much used for real communication in English. Some used it for quick communication, but not many for tutorials or group work through videoconference. Students declared having found other ways of communicating with their classmates and with the teacher (Facebook, Tuenti, e-mail, etc.).

\subsection{RESULTS OF TEACHERS' SURVEYS}

'Teachers' access to the virtual campus was not considered very regular $(73,1 \%)$. Trainers, in general, declared that uploading documents and creating exercises was easy $(77,1 \%)$ and pointed out the usefulness of self-assessment tests (91,6\%) and task-boxes. However, they also admitted not having made regular use of the forum. An interesting point is that they thought they had answered regularly to the questions students asked them (84,9\%) while students complained about the lack of response from teachers through the forum.

For teachers, videoconferences also represented a great innovation over traditional online distance $(87,4 \%)$ for foreign language teaching and learning (89,9\%). They also viewed them as good tools for the active practice of oral skills $(88,2 \%)$ but some commented that "not all contents can be adapted to this type of methodology; each subject is different". Besides, some trainers argued that face-to-face interaction "provides teachers and learners with much more information and a different quality of feedback".

Many of the teachers agreed that emotions could be easily transmitted through this medium $(84,9 \%)$; that classes could be very interactive $(85,7 \%)$; and, that small group work was possible at breakout rooms ${ }^{9}$ (88,9\%). Nevertheless, to this regard, some teachers commented that this methodology could be "supplemented with communication through well-known social networks" and "collaborative work through web 2.0 tools". As in the case of students, the most appreciated tool was the possibility of recording and

\footnotetext{
9 Breakout rooms are separated virtual spaces for small group work and discussion within whole class group videoconferences. Teachers group and allocate students separately and can freely move from one room to another, interacting with trainees. Students communicate with each other (through voice and chat) and work collaboratively on their whiteboards. The resulting presentation can be saved and shared with the whole class group afterwards.
} 
viewing the sessions $(92,4 \%)$ so that students could revise and teachers were able "to check on learners' linguistic performance".

Teachers believed that they had not used the chat and the instant messenger for synchronous communication with students or for tutorials as much as they could have (46,3\%). Regarding on-campus classes, they thought that they were a very necessary complement to on-line teaching $(96,6 \%)$.

Teachers' surveys also showed that most of the instructors (64\%) were aged 31-40 or below, 18\% were aged 26-30, and 6\% aged 20-25. Most of teachers (87\%) had only experience and knowledge about the use of the virtual campus; only $12 \%$ were familiar with other ICT devices apart from ordinary virtual campus tools; and other 12\% did not have any knowledge or experience at all with ICT. Regarding this point, it can be argued that most of the teachers were familiar with the use of the virtual campus but at a very basic level. Even though most teachers were aged 26-40, very few have knowledge about other ICT tools, like videoconferences, blogs, wikis, and so on, which, on the contrary, were very familiar to students.

Regarding teachers' working circumstances, the vast majority of teachers (88\%) were working in other institutions or in other programmes within the same university, which would explain why they thought that blended learning allowed them to conciliate their work at the university with other activities.

\subsection{RESULTS OF TEACHERS' INTERVIEWS}

Teachers, in general, accessed easily online classes, but reported the same technical problems, which they believed "affected greatly interaction, the development of the session and the cohesion of the group".

Although the development of classes differed much from some subjects to others, in general, they used the structure of a presentation of key concepts on PowerPoint, interspersed with some internet routes, more or less sharing of desktops, video or sound files, some practical activities, and some collaborative work. However, very few teachers declared having made use of breakout rooms for small group work.

For some teachers, on-line classes were very interactive and allowed collaborative work ("breakout rooms have been essential for small groups discussion"); for others, online groups had to be reduced in order to ensure all the students' participation ("some students find it easy to hide and refuse to participate, stating that their microphone does not work"); for a few, some changes should be introduced to make interaction richer and foster group cohesion, in a similar way to on-campus classes ("the kind of interaction and group belonging fostered in face-to-face classes is impossible to get through 
A SPANISH UNIVERSITY CASE STUDY: USER'S PERCEPTION OF BLENDED METHODOLOGY USED...

videoconferences"). To this regard, they suggested having the first in-campus class before any online session took place; meeting the students before the beginning on online teaching; having personal information from students before staring the classes; and making use of Web 2.0 tools "to increase interaction and group feeling between students and teachers and students among themselves".

For a few teachers, in on-line interaction, "some face-to-face features (body language or sound clarity) were lost" and many of the elements to improve students' communicative competence in the foreign language (pronunciation, grammatical correctness, syntax construction) were "reduced in honour of economy of language because of the medium". They believed that these were too important aspects in language proficiency which could not be disregarded "at any language level, but especially when the aim is to reach the C1-level".

Teachers, like students, considered on-campus sessions a necessary supplement to on-line classes and many admitted that they preferred them over on-line ones. Many of them argued that the personal bounds and the methodological procedures carried out during these classes "didn't take place in on-line sessions". However, unlike learners, teachers thought that both types of classes were prepared so that students could "participate as much as possible and practice their English skills all the time".

Virtual campus tools worked well for teachers too. However, some tools were found to have been neglected: the agenda was not used because teachers announced important dates or pieces of information through the bulletin board; the links section, was hardly filled in, as teachers claimed that they had no time to upload and update their links, and only a few of them wrote comments and filed them in different folders; the self-assessment tool was mainly used to create self-assessment tests, as only two teachers created classroom or reinforcement exercises using this tool. Besides, the types of exercises used were mainly of the multiple choice, cloze and open-ended questions-type, and only one teacher wrote comments to students on right and wrong answers. When asked, they admitted that students could have benefited from self-assessed reinforcement activities and comments, as well as from more exposure to linguistic input. However, they complained that the system was too rigid to allow them prepare questions in other formats at home and then import them to the virtual campus, so most of the times exercises had to be typed twice.

About the use of the forum, teachers declared that they did not use it neither for collaborative work nor for class discussion. Besides, when asked about the students' complaint about the delay in the answer to questions posted on the fora, they admitted that, due to time restrictions, it was more practical for them 
to answer via e-mail, although they though that "it would have been a wonderful chance for real communication in English".

As stated before, the chat and the instant messenger were introduced at the university late at the beginning of the second term, so neither teachers nor students had the chance to receive formal training in this tool. Some teachers used it for quick communication with university mates but only one declared having used it for tutorials with students. All of them lamented the underuse of "a tool which could have fostered communication in the target language".

\subsection{RESULTS OF STUDENTS' FINAL GRADES}

In the first term, most of the students passed their subjects in the ordinary examination period (72\%), which proved the level of English of students when entering the course. From the ones with pending subjects in the retake examination period held in July, the vast majority of them seemed to have reached the required level of English. Only 32\% of them still failed some courses. However, the amount of fail courses was less than in the first semester. This fact might prove that the students who had entered the course with a lower level of English had managed to improve their linguistic English.

During the second semester, results suggested that, as learners developed further their English communicative skills, considerably less students (only $15 \%$ ) failed courses on the ordinary examination period. Like in the first semester, almost the same amount of students with pending subjects during the retake examination period (33\%) succeeded. This might reinforce the hypothesis that students who had entered the course with a lower level of English had improved their proficiency in English.

Regarding the pass grades range, results showed that, at the beginning of the course, the majority of pass grades were between 6.6 and $8^{10}$, being followed by those between 8.1 and 10. However, during the retake examination period, most of the pass grades were ranged 5 and 6.6. These results could reinforce the ideas that 1) most of the students entering the course had already a high level of English, and 2) students improved their English linguistic skills, as the retake exams held in July showed the improvement in the grade range in comparison to the grades of students obtained in February.

Nevertheless, during the second term, possibly as the students communicative competence in English improved, in the ordinary examination period, the two highest ranges (6.6-8 and 8.1-10) were equalled. This fact might

\footnotetext{
10 Over a maximum grade of 10 .
} 
A SPANISH UNIVERSITY CASE STUDY: USER'S PERCEPTION OF BLENDED METHODOLOGY USED...

have been explained by the improvement of English competence of those students in the B2 level or below. As in the first term, the passing grades during the retake examination period were ranged from 5 to 6.5 , which reinforces the hypothesis that the students with lower level of English had also improved their level.

\section{CONCLUSIONS, RESTRICTIONS AND IMPLICATIONS}

The aim of this study was to analyze the perceptions of both teachers and students on the effectiveness of the blended-learning methodology in foreign language learning used within the Master's Degree in Bilingual Education at Nebrija University. Although this research fulfilled its objectives, certain restrictions needed to be drawn. To begin with, the number of students enrolled in the course was not very high, and not all of them filled in the survey. Besides, the students attending the Master's degree were very young. For all those reasons, the results of this study could not account for the whole of students' community but only for a part of it. Further research on a larger number of students and on different age groups seemed necessary in order to provide a wider perspective on the issue.

From a pedagogical perspective, the following points show the conclusions about the perceived effectiveness of students and teachers about blendedlearning methodologies being used for EFL learning.

Firstly, blended learning can offer students plenty of opportunities for effective and independent foreign language learning. The use of English as the vehicular language made students communicate extensive and intensively in the target language. Likewise, classes through videoconferences represent an improvement over traditional online distance learning as regards foreign language learning through the integration of synchronous modes of communication for intensive oral linguistic practice to the asynchronous virtual campus ones, typical of distance online learning.

The combination of on-line, on-campus classes and the use of virtual campus tools contributed to the increasing amount of exposure to the target language as well as a real and meaningful reason to communicate throught it. Also, the option of re-watching recorded sessions became a good linguistic training resource. Furthermore, the workshops during the two immersion periods represented as well a good chance for learners to practise their linguistic skills and be aware of their improvements in English proficiency which encouraged them to learn more. Nevertheless, the fact that some virtual campus and on-line classes tools were neglected or misused reduced the opportunities for a greater 
exposure to English. In this respect, the introduction of familiar social networks or Web 2.0. tools might multiply the chances of real interaction in English too.

Blended-learning offers students the opportunity of becoming more autonomous FL learners. The great majority were active participants in the activities, and took full responsibility for their own learning. However, the progressive independence of students can not be considered not a process which comes on its own. Much training with students is necessary, through group work, independent research or further consultation of additional learning material, for instance.

Secondly, students can improve their linguistic competence in English through blended learning but some CALL core or supplementary material might be necessary in blended learning for foreign language learning. A major concern among teachers was the belief that some face-to-face features were not present or were reduced due to the immediacy of the on-line medium, and that the detailed linguistic analysis required from students at a B2-C1 level could not be easily addressed through this medium. This is not a minor issue considering the level that the students were required to reach. For that purpose, linguistic training needs to be intensive and extensive. The greater the exposure the quicker the learning, but some linguistic learning tools might have needed to be included in the programme in order to ensure the practice of isolated linguistic items at a certain linguistic level. In this sense, transforming contents into multimedia or providing hyperlinks to CALL-type of exercises could have possibly helped students improve their communicative competence in English and reinforcing the learning of English skills and subkills.

Furthermore, the right blend of synchronous and asynchronous learning and communication modes can optimize foreign language learning, as well as build and support e-learning communities. Asynchronous communication and learning tools need to be combined with synchronous learning experiences in order to promote personal and cognitive participation and communication. As interaction through computers is characterized by immediacy, some linguistic and extralinguistic aspects might be lost. To this respect, foreign language studies through blended learning should try to avoid losing its main purpose, that is, to improve students' linguistic performance through communication in the target language. For that purpose, it is advisable 1) to combine and balance online-classes, oncampus classes and the use of virtual campus tools; 2) to hold on-line classes in small groups as much as possible to ensure the active participation of all students; or 3) to introduce some changes to create, raise and hold interaction and group cohesion between students and teachers, like for instance, to hold a meeting with students before the actual beginning on online teaching, or to use 
A SPANISH UNIVERSITY CASE STUDY: USER'S PERCEPTION OF BLENDED METHODOLOGY USED...

Web 2.0 communication tools (blogs, wikis, etc.) or the well-known social networks (Facebook and twitter). Foreign language learning needs, as any other type of learning and even more, that students can interact in a stress-free environment in order to raise their motivation and confidence.

Finally, blended-learning tools can transform foreign language learning. In the introductory year of the programme, some technical problems during on-line classes hindered the high interactivity which these tools could offer. To this respect, higher education institutions need to be aware that both a higher expertise of participants and a reliable technical support are necessary in order to help these programmes succeed.

Besides, as it has been discussed above, some blended learning tools were misused or neglected. Although the blend used at the degree relied on the typical elements used in blended learning, each teacher could freely choose to use some more than others. Certain tools which could be considered ideal to foster cooperation, group work and communication in the foreign language were often neglected or misused. Therefore, the programme probably did not take advantage of all the transformative potential that blended learning can offer beyond the sheer additional flexibility or supplementary materials online. In this sense, staff and students' training in blended-learning tools is essential. On-line classes differed from some subjects to others but, in general, they were more teacher-led as many teachers felt insecure and lacked skills in this methodology.

\section{FINAL REMARKS}

To conclude, it can be said, that, the blended learning methodology used at the programme showed to be effective although some improvements could still be introduced in order to reach its full potential. On the one hand, the success or failure of blends used for foreign language learning lies on the faculty and institution's adoption of effective and flexible blended-learning practices which can adapt to the different learning and teaching situations. On the other, implementing blended learning, for content or foreign language learning, or for both, implies that participants (teachers and students) rethink and redesign the teaching and learning roles of methodological resources, tutors and learners into a cognitive, holistic, active and connected learning experience. Likewise, in order to create a blended-learning environment, it is necessary institutional support to train teachers in this new methodology, time to introduce changes, technical assistance and guidance when problems arise, and staff's commitment with the new method. None of them can exist without the other. 


\section{REFERENCES}

Albrecht, B. 2006. "Enriching students experience through blended learning". $<$ http://net.educause.edu/ir/library/pdf/erb0612.pdf $>$. (Accessed 22 June 2012).

Alcides Parra, L. 2008. "Blended learning, la nueva formación en educación superior". <www.revistaavances.co/objects/docs/.../a9_art9_blended_ learning.pdf $>$. (Accessed 28 June 2012).

Andrews, R. and C. Haythornwaite. 2007. The SAGE Handbook of e-Learning Research. London: SAGE Publications Ltd.

Bartolomé, A. 2008. "Entornos de aprendizaje mixto en educación superior". <http://e-spacio.uned.es/fez/eserv.php?pid=bibliuned:Ried-2008-numero10001\&dsID=Documento.pdf $>$. (Accessed 21 May 2012).

Bonk, C. J., Kim, K. and T. Zeng. 2005. "Future directions of blended learning in higher education and workplace learning settings". $<$ http://www.publicationshare.com/c083_bonk_future.pdf>. (Accessed 10 May 2012).

Bonk, C.J. and C.R. Graham, 2004. "Blended Learning Systems: Definition, Current Trends, and Future Directions". Handbook of Blended Learning: Global Perspectives, Local Designs. San Francisco, CA: Pfeiffer Publishing.

Carman, J.M. 2005. "Blended-learning design: five key ingredients". <http:// www.agilantlearning.com/pdf/Blended\%20Learning\%20Design.pdf $>$.

(Accessed 23 June 2012).

Downes, S. 2007. Learning Network in Practice. National Research Council of Canada: Institute for Information Technology.

Dziuban, C.D., Hartman, J. and P.D. Moskal. 2004. "Blended Learning". $<$ http://net.educause.edu/ir/library/pdf/erb0407.pdf>. (Accessed 21 May 2012).

Egbert, J and E. Hanson-Smith. 1999. CALL Environments: Research, Practical, and Critical Issues. Alexandria, VA: TESOL.

Ellis, R. 2004. Task-based Language Learning and Teaching. New York: Oxford.

European Commission. 2006. "Los europeos y sus lenguas". Eurobarómetro especial, 243 <http://ec.europa.eu/spain/pdf/eurobar_lenguas_es.pdf>. (Accessed on 3 October 2013).

European Commission. "The Bologna Process - Towards the European Higher Education Area”. 2013. <http://ec.europa.eu/education/higher-education/ bologna_en.htm>. (Accessed 20 June 2012). 
A SPANISH UNIVERSITY CASE STUDY: USER'S PERCEPTION OF BLENDED METHODOLOGY USED...

Garrison, D.R. and H. Kanuka. 2004. "Blended Learning: Uncovering its Transformative Potential in Higher Education”. <http://commons.ucalgary.ca/ documents/Garrison\%20\&\%20Kanuka\%20BL\%20Abstract\%20IHE.pdf>.

(Accessed 22 June 2012).

Garrison, D.R. and N. Vaughan. 2008. Blended Learning in Higher Education: Framework, Principles and Guidelines. San Francisco: Jossey-Bass.

Halbach, A., Lázaro, A. and J. Pérez. 2010. "La acreditación del nivel de lengua inglesa en las universidades españolas". <http://www.britishcouncil.org/ spain/sites/default/files/publications/Acreditacion-ingles-universidadesespanolas.pdf>. (Accessed 11 May 2012).

Halbach, A., Lázaro, A. and J. Pérez. 2013. "The Role of the English Language in the Post-Bologna Spanish Universities". <http://www.mecd.gob.es/dctm/revista-de educacion/articulosre362/re36204.pdf?documentId=0901e72b816fb9a0>. (Accessed 8 October 2013).

Harmer, J. 2010. The Practice of English Language Teaching. Cambridge: Pearson Longman.

Hrastinski, S. 2008. "Asynchronous and Synchronous e-learning". <http:// net.educause.edu/ir/library/pdf/EQM0848.pdf>. (Accessed 22 June 2012).

Hubackova, S. and M. Ruzickova. 2012. "On the effectiveness of e-Learning and the process of teaching". <http://www.world-education-center.org/ index.php/P-ITCS/article/viewFile/730/366>. (Accessed 1 March 2013).

Hubackova, S. and I. Ruzickova. 2012. "Pedagogical and psychological aspects of e-Learning”. <http://www.world-education-center.org/index.php/P-ITCS/ article/viewFile/747/381 >. (Accessed 1 March 2013).

Koohang, A., Riley, L. and T. Smith. 2009. "E-learning and constructivism: from theory to application". <http://ijklo.org/Volume5/IJELLOv5p091109Koohang655.pdf>. (Accessed 23 June 2012).

Little, D. 2011. "The Common European Framework of Reference for Languages: A Research Agenda”. Language Teaching 44 (3): 381-393.

Long, M. 2005. Second Language Needs Analysis. Cambridge: Cambridge University Press.

McLaren, B.M., Koedinger, K. and M. Scheider. 2004. "Toward cognitive tutoring in a collaborative, web-based environment". <http://pact.cs.cmu.edu/koedinger/ pubs/McLaren,\%20Koedinger,\%20Schneider,\%20Harrer\%20\&\%20Bollen\%200 4.pdf>. (Accessed 12 September 2012). 
Richards, J. C. 2001. Curriculum Development in Language Teaching. Cambrigde: Cambridge University Press.

Rosset, A. and R. Vaughan. 2006. "Blended Learning Opportunities". <http:// www.grossmont.edu/don.dean/pkms_ddean/ET795A/WhitePaper_BlendLea rn.pdf>. (Accessed on 9 May 2012).

Sharma, P. and B. Barrett. 2007. Blended Learning - Using Technology In and Beyond the Language Classroom. Oxford: Macmillan Publishers Limited.

Siemens, G. 2004. "A Learning Theory for the Digital Age". <http:// www.connectivism.ca/>. (Accessed on 9 June 2012).

Singh, H. 2003. "Building Effective Blended Learning Programs". <http:// jw1.nwnu.edu.cn/jpkc/jcxy/jxsj/web/zhuantixuexiziliao/Building\%20Effectiv e\%20Blended\%20Learning\%20Programs.pdf>. (Accessed 11 June 2012).

Stacey, E. and P. Gerbic. 2008. "Success Factors for blended learning". <http:// www.ascilite.org.au/conferences/melbourne08/procs/stacey.pdf>. (Accessed 11 May 2012).

Thorne, K. 2003. Blended Learning: How to Integrate Online and Traditional Learning. London: Kogan Page Publishers. 